\title{
Empowering Researchers and Knowledge- Producing Organizations for Evidence-Informed Health Policy Making: Interventions in the Iranian Health System
}

leila Doshmangir

Tabriz University of Medical Sciences

Hakimeh Mostafavi ( $\square$ hakimeh_mostafavi@yahoo.com )

Shaheed Beheshti University of Medical Sciences

Reza Majdzadeh

Tehran University of Medical Sciences

\section{Research}

Keywords: Evidence-informed Health Policy, Health System Research, Health Policy, Policy Interventions

Posted Date: August 18th, 2020

DOI: https://doi.org/10.21203/rs.3.rs-58814/v1

License: (c) (i) This work is licensed under a Creative Commons Attribution 4.0 International License.

Read Full License 


\section{Abstract}

Background: Providing appropriate information to policymakers by strengthening evidence-based capacity is a key factor in the development of evidence-based policy making (EIPM). This study aims to examine the necessary interventions in the Iranian health system for empowering researchers and knowledge-producing organizations to strengthen EIPM.

Methods: This qualitative study was conducted using interviews and document review. The views and experiences of enterviewees were extracted through semi-structured interviews. Purposive sampling was used and continued until data saturation. Thematic framework analysis and MAXQDA 12 software were used for data analysis.

Results: Necessary interventions for empowering researchers and knowledge-producing organizations were categorized into health system interventions, community-based interventions, organization interventions, and individual interventions.

Conclusion: Incompatibility of health policy decisions with scientific evidence derived from research highlights the importance of creating a common language among health policymakers and researchers. In this regard, developing scientific and practical interventions, educating health researchers on knowledge translation, and using mechanisms and networks for effective interaction will be constructive.

\section{Contributions To The Literature}

- This study showed that although policymakers and researchers do not interact constructively with each other, they acknowledge the need for this interaction.

- Our study also showed that community and health organizations should be considered to empower researchers and Knowledge-Producing Organizations.

- These findings contribute to recognized gaps in the knowledge about ways of empowering the health researchers and the factors affecting their capability in the country.

\section{Background}

All governments resort to mechanisms such as public policy to solve the problems facing the society, improve conditions, and exploit opportunities. Various models and frameworks have been proposed by different groups and organizations for enhancing public policy $(1,2)$. One of these models that has gained momentum in the last 10 years is evidence-informed policy making (EIPM) (3). EIPM is an approach to policy making that takes into account the political context, availability of resources and, people and customer experiences in order to provide the right evidence at the right time in the right language for policy making $(4,5)$. This approach enables policymakers to make informed decisions using the best available evidence, which will ultimately improve health system performance. 
In addition to the demand for evidence among policymakers, supply of appropriate evidence to policymakers strengthens producer capacity and has a key factor in the expansion of EIPM. The increased use of evidence in policy making means stronger capacity for evidence production in both the demand and supply side(6).

The International Conference on EIPM, which was held in Nigeria from 27 to 29 February 2012, discussed the importance of EIPM and the role of policymakers in implementing this approach, while highlighting the lack of evidence on effective strategies for empowering knowledge-producing organizations to implement such policies. Uptake of the right research evidence in the policymaking process and developing necessary strategies are key issues in strengthening EIPM (7).

Use of evidence in policy making involves a wide range of interrelated issues such as the scope and nature of evidence, how to use evidence, patterns of evidence use in the policymaking process, dissemination and exchange of evidence, collection and retention of evidence, review of its results and effectiveness, and research capacity to support such initiatives. Advocates of EIPM argue that the depth and quality of knowledge used by policy makers influence the effectiveness of policies. It is necessary to take steps to use appropriate methods, interventions, and strategies to produce the knowledge needed by policymakers and strengthen this policy-making approach(8). In addition to other important factors such as the failure to correctly identification of the problem or issue, and the lack of a problem-solving function that causes the limited evidence-based policy making; lack of research-based solutions also is critical. Policy making must be knowledge-based and reliant on appropriate analytical tools. Researchers and knowledge-producing organizations such as universities play a significant role in this regard.

Studies and the research evidence can help health policymakers and managers to evaluate current systems and, design new policies and services based on their knowledge of failures and successes(9). In addition, evidence using enables policymakers to implement policies based on the best available evidence(10). Some critics believe that there is a gap between policy making requirements at the national level, needs of a society that must be met, and policy priorities and what motivates researchers to do research $(11,12)$. On the other hand, sometimes researchers provide policymakers with massive amounts of evidence that confounds and complicates decision making.

Although in recent years various measures and interventions have been implemented in Iran's health system to strengthen and institutionalize EIPM, in reality, many policy decisions are still not informed by evidence. In many cases, health policies are rushed, politicized without sufficient research and evidence and, without scientifically getting to the root of the problem. Each year, new issues and problems arise in the Iranian health system with various responses from policymakers, but many problems remain unsolved. This, again reinforces the importance of EIPM. In general, discussions of the practical applications of evidence in health policy have been less extensive, and there has been much less discussion about Iran in the literature, even though evidence use has been receiving increasing attention in the country in the recent years. There is no comprehensive experience or evidence on how to strengthen knowledge producers' capacity to develop EIPM in Iran. Therefore, this study aims to examine the 
knowledge and skills required for strengthening EIPM in researchers and knowledge-producing organizations and, also developing appropriate empowerment programs.

\section{Methods}

In this qualitative study, we collected data through interview and documentary review. Semi-structured interviews were used to collcet the opinions and experinces of health key experts about current empowering programs of researchers and knowledge-producing organizations on production and translation of evidence required for policy makers and providing appropriate empowering programs in Iran.

Participants including researchers, policy makers, policy takers, faculty members were selected through purposive sampling method. Douments were also selected from various relevant organizations. Sampling were continued to reach saturation. Totally, we conducted 18 interviews. Table 1 provide demographic caractristics of participants. Interviews were conducted in the participants office or the place that they prefereed. Before starting the interview, informed consent were filled by the participants. We insured participants that they can exit from the study whenever they prefer. Interviews were conducted based on the interview guide. Interview guide had two parts including demographic quations and main questions based on of aims of the study. To finalyse the interview guide, three preliminary interviews were conducted. Interview guide is attached in Appendix 1 . Four interviews were conducted by sending an email to the participants and asking them to write your answers on the paper or record your ansers to the questions.

After each interview, they were transcribed verbatim. To improve rigor of the study, various activites were done. To increase credibility, dependability, dependability, conformability and triangulation, we used serveral resources for data collection such as conducting interviews with various participants and conducting documents reviews. After conducting interviews, transcribed files were sent to participants to cofirm them or make any changes they want. To increase transferability, purposive sampling were used(13).

Five stages of thematic framework analysis approach including familiarization, identifying a thematic framework, indexing, charting, mapping and interpretation was followed to analyse data.

\section{Results}

Based on the interviews, the necessary interventions for empowering researchers and knowledgeproducing organizations to produce and translate the appropriate evidence for health policy in Iran can be divided into four themes: health system interventions, community-based interventions, organizational interventions, and individual interventions. Description of each theme is provided below.

\section{Health System Interventions}




\section{Education system}

Review of the documents and analysis of interviews indicate that one of the most important measures for empowering researchers and knowledge-producing organizations is to hold relevant specialized training. According to most interviewees, training is a key step in developing a skilled workforce and a useful tool for improving the quality of policy-related research. Formal education in universities (e.g. through specifically designed courses and/or by including relevant discussions in other courses), shorter training programs, workshops, and on-the-job training are some of the suggestions made by the participants.

"Any change in this aspect must begin from the top, that is, from the national education system." (1-3)

\section{Research cycle management}

Issues related to research cycle management include developing national strategies aimed at continuous and constructive cooperation for strengthening EIPM among knowledge producers (including researchers and knowledge-producing organizations) and knowledge users, providing support for policy-related data collection, archival, maintenance and distribution, and facilitating access to relevant data by users such as students and researchers.

"Evidence-production networks in the country are faced with poor management. For example, research priorities in the networks of the Ministry of Health and the way these priorities are established are unclear." (1-14)

\section{Evaluation and assessment}

According to many of the interviewees, changing the evaluation and assessment system, defining motivators, changing the reward system, especially for faculty members and researchers with respect to policy-focused knowledge translation, and changing researcher ranking method in the Research Department of the Ministry of Health play a significant role in the promotion of this policy approach.

"An issue that must be addressed is the evaluation system. faculty members and students are only concerned with producing articles, not being responsive to the needs of different groups and the society as a whole." (I-10)

\section{Community-Based Interventions}

\section{Culture generation}

The interviewees believed that evidence-based health interventions and policies must be promoted and accepted by the wider community. If this becomes the prevailing practice, it will lessen the impact of conflicts of interest and political inclinations on decision making. 
"We all know the significant impact and role of pressure groups in the world of policies. We must force policy making toward demanding appropriate evidence from researchers and research centers. Once we build this culture, researchers and knowledge producers will also have to improve to keep pace with policymakers' demands." (I-7)

\section{Media}

According to the interviewees, the media plays a key role in promotion of EIPM. Transparency and reporting the results of policies and plans that are informed or uninformed by evidence can contribute to these efforts.

"The media, just like people and experts, can discuss policy topics. If the media are familiar with the literature, they will consider the extent to which policy making is evidence-based whenever a policy is made at any level." (I-4)

\section{Organizational Interventions}

Organizational interventions include training programs, knowledge management and organizational communication management, and research cycle management.

\section{Training}

According to some of the participants, one of the most appropriate educational methods is short-term specialized training programs which can be defined at the organizational level. The nature of these programs and the course subjects and contents will develop the skills required by researchers and other people involved in knowledge production, allowing them to meet the needs of policymakers. In most cases, short-term training programs are designed and implemented for two main reasons: to teach scientific and technical skills and change organizational behavior.

"It's necessary to assess the needs of the consumers of knowledge products and develop training programs accordingly." (1-9)

Use of modern teaching techniques such as distance education and defining and planning training programs based on policymakers' expectations were other issues raised by the participants of this study.

\section{Knowledge management and organizational communication management}

According to the interviewees, in the context of EIPM, knowledge management is a systematic approach to understanding and using knowledge or information and making it available to policymakers at the right time, thus allowing them to make informed decisions. The findings of the present research indicate that achieving evidence-based or evidence-informed policy making requires knowledge management to be focused on projects and knowledge development, establishing the relevant knowledge base, the exchange and sharing of knowledge among the employees of the organization, and training. 
"There should be a system in place for registering policy researchers and monitoring their scientific and professional activities." (1-1)

\section{Research cycle management}

Effective research cycle management is an important consideration in interventions for empowering researchers to strengthen EIPM. Research cycle begins with the proposal of a research idea and design and continues until evidence production and application. By focusing on the production of credible evidence, effective research cycle management leads to identification of more influential and higher quality research and prepares the ground for better use of evidence by users such as policymakers.

"It's especially important to pay attention to the quality of data produced in organizations." (I-12)

The findings indicated that research cycle management emphasizes the adoption of strategies for directing knowledge creation toward more influential and higher quality research and preventing the unhindered publication of "pseudo-research".

\section{Individual Interventions}

\section{Behavioral-motivational interventions}

Motivational interventions play a key role in the performance of researchers and knowledge-producing organizations and are critical to strengthening EIPM. Knowledge about the personal characteristics of individuals in an organization and the use of various motivators will enable them to communicate more effectively with their audience and strengthen this policy approach. According to many of the participants, multidimensional behavioral-motivational interventions have a significant effect on individual performance.

\section{Knowledge of policy making and policy analysis}

According to the interviewees, one of the issues that is often ignored in discussions about strengthening EIPM is the fact that there is a considerable gap between the world of research and the world of policy making, which acts as a major barrier to expanding this policy approach. To reduce this gap, researchers and faculty members need to become familiar with the basic concepts and principles of policy making and policy analysis and apply them in their research endeavors.

"Individuals and organizations that seek evidence-informed policy making must possess both policy making and evidence-related knowledge." (1-3)

The participants believed that problem for science and evidence-based policy comes when politicians and other political actors decide to discredit the science on which a conclusion is based or bend the science to support their policy position. This is called policy-based evidence as opposed to evidencebased policy. Researchers who possess the knowledge of policy making can prevent this and use policymakers' language to promote EIPM. 


\section{Knowledge of policy evidence production and translation}

The interviewees were of the opinion that the gap between the knowledge produced by researchers and organizations and, the decisions and policies made by senior officials is a key challenge in the implementation of EIPM. Interventions are needed to bridge this gap, including the provision of skills and knowledge of policy-related evidence production and translation. Knowledge of knowledge translation was highlighted by the participants as a key factor in strengthening the adoption and application of research results by policymakers, which will enable them to make informed, knowledge-based decisions and policies.

"Instruments that can contribute to informed policy making and decision making and translating evidence into the language of policymakers aren't used extensively. Policy makers don't receive the necessary skills. Employees almost never reach the level of knowledge translation in evidence-informed policy making and remain at the level of producing articles, mostly at the national level." (1-5)

\section{Knowledge of science communication}

Communicating science to policymakers is one of the skills that were underscored by the interviewees. They argued that science communication must be in both oral and written format. Use of instruments in the language of policymakers can attract their attention to a specific problem and prompt them to implement appropriate interventions.

"In our country, there is a weak link between knowledge producers and policymakers. Each policymaker must be guided by a number of researchers. We can argue that these two groups are still in dire need of better communication." (1-14)

According to the participants, familiarity with the characteristics of research data users (i.e. policymakers and decision makers) and the nature of their work allows for establishing more effective science communication, conducting research with the participation of decision makers, and identifying the social barriers to changing evidence users' behavior.

\section{Knowledge of the health system}

To institutionalize and strengthen EIPM, researchers and knowledge-producing organizations need to understand and be aware of the functions and goals of the health system, its different sections and components, how it affects and is affected by other sectors, and the history and outcomes of important actions and policies implemented within the health system. Some interviewees believed that some issues such as systems' thinking and systems' dynamics can also be influential in better understanding of the outcomes and effects observed within the health system and using this knowledge to inform policies.

\section{Discussion}


In the present research, necessary interventions for empowering researchers and knowledge-producing organizations to strengthen evidence-informed policy making (EIPM) in Iran were discussed at four levels, i.e. health system, community-based, organizational, and individual interventions.

Although developed countries have a long history of evidence utilization for policy making, studies have found that even countries such as Australia, Canada, UK and Belgium actively engage in training and updating health policymakers' capabilities and encourage them to use of evidence in practical decisions. Various studies have shown that researchers are mainly concerned with encouraging more evidence use in decisions and policies made by health care managers and prompt educational interventions for managers at all the levels of the health system. The participants of these interventions include policymakers at the macro level of the health system, managers and experts at the level of health ministries, and even health care organizations.

An effective way of enhancing the knowledge and capability of health policymakers and managers in developing countries is to hold training courses and use the practical examples of policy formulation and policy briefs(12). A review of the literature indicates that holding workshops and answering the participants' questions has been the prevailing intervention. Online education through websites or e-mail has been the second most effective intervention, followed by holding short-term university courses.

Given the existence of reputable universities in Iran, there are experienced professors and graduates of the best universities around the world that provide education to students in four-year graduate programs on health policy. This allows the Ministry of Health and Medical Education as the steward of education in this sector to devise different types of training programs for empowering managers and policy makers within the health system. Due to the country's financial constraints, managers could be charged a fee for registering in workshops and/or modern educational techniques such as online education and distance learning could be employed in the training of managers and policymakers.

In addition, due to the lack of a common language between researchers and policy makers, specific mechanisms and networks can be established for effective communication between these two groups $(14,15)$. It is necessary for researchers and policymakers to share their views in all stages of the EIPM, including prioritization, research design, and reporting of the results(16). Evidence suggests that in developing countries, there is little research in various fields of medical science, including health policy and economics, behavioral sciences and epidemiology, and often these studies are either not published or are not communicated well to the audience and, do not lead to the application of the underlying evidence. Research studies are often isolated and discontinuous and thus are not responsive to the problems and needs of the society.

An important measure that must be taken by the managers of any organization, including centers for research in medical and non-medical fields, is assessing employees' awareness of knowledge transfer and translation. To strengthen EIPM, it is necessary for policymakers to effectively use the produced knowledge. Currently, many organizations have a weak knowledge base and do not value and exploit their knowledge capital. 
The findings of this study showed that the combination of knowledge management and organizational communication management is a good option for presenting and disseminating the best and most appropriate knowledge within the organization. Training is an essential element and an indispensable part of the human development activity in this regard. Our findings indicated that providing researchers and knowledge-producing organizations with relevant training will change their attitude and enhance their knowledge and skills, thus playing a key role in strengthening EIPM. Uneke et al. believe that holding training courses is a major step toward bridging the gap between research and practice and strengthening $\operatorname{EIPM}(17,18)$. The concept of research is founded on systems thinking, which is purposeful and seeks to identify not only the challenges faced by the society, but also the solutions required to address them. Research management in the field of medical science requires managing and coordinating research activities, determining research priorities, formulating strategies and policies, and managing information(15).

Knowledge management and organizational communication management optimizes the relationship between an organization of firm and its customers, partners and suppliers to maximize opportunities(19, 20). Production of knowledge and science is the main mission of universities and research centers, and this can only be achieved through research. However, it must be noted that being evidence based is an essential characteristic of modern science. Research in the area of health policy making is a systematic process for knowledge production to enhance the functions of the health system, i.e. service provision, resource generation, financing, and stewardship, and contribute to attaining its goals and ultimate objective, which is to enable all people to achieve their fullest health potential $(21,22)$.

Today, in order to more successfully implementation of EIPM, knowledge-producing organizations must pay special attention to knowledge management and organizational communication management and increase their communication with their audience, including decision makers and policymakers. Our findings highlight the importance of providing the right knowledge at the right time, that is, at the point of decision making, by implementing knowledge management in health care organizations. Shahmoradi (2017) argues that it is very important to use appropriate tools and user-friendly systems for knowledge management as it can significantly improve the quality of decisions made in various organizations(23, 24).

Researchers play a key role in exploitation of knowledge. Therefore, empowering them in knowledge exploitation activities is imperative(25). A key requirement in these initiatives is taking measures for disseminating the knowledge obtained from research(26). In this regard, one of the necessary interventions is to enhance the understanding of knowledge translation in this group. Knowledge translation includes a wide range of activities that can be used to effectively convey the message of research to the target group (in this case, the policymakers) $(27,28)$. The study of majdzadeh et al. showed that researchers tend to overestimate their knowledge translation activities, making it necessary to train and familiarize them with all the aspects of knowledge transfer and translation as well as the methods of evaluating these activities, which can be highly effective in operationalization and use of research results(29). Dakhesh et al. observed that many researchers only seek to enhance the level of 
awareness among research audiences and stakeholders by relying on passive dissemination of knowledge, while not paying much attention to changing users' performance and behavior as the main goal of knowledge translation(10).

The findings of the study indicate that strengthening the EIPM requires researchers to always provide policymakers with appropriate evidence-based insights and scientific advice to help them in their decision making. However, a serious gap still exists in Iran, where researchers' recommendations do not produce desirable results or lead to adoption of inefficient and ineffective policies that fail to solve the general problems faced by the society and the health system.

To successfully communicate and operationalize policy recommendations, the acquisition of knowledge related policy-making and the translation of knowledge, including how to formulate and publish policy briefs or hold policy discussions, and how to find and clarify policy problems are suggested (30-33). Science communication is an important intervention for strengthening EIPM and was highlighted by many of the interviewees. It must be noted that science communication is not limited to empirical science, but also includes non-empirical reasoning (e.g. philosophy, techniques, and skills)(34). The former can be acquired and is transferrable, but the latter is a larger part of knowledge the is intuitive and not acquirable. This form of knowledge requires special individual abilities and cannot be transferred to others $(35,36)$. In the context of communication management and empowering researchers to strengthen EIPM, intuitive knowledge is not taken into account and the focus is on explicit knowledge that can be codified and thus be transferred and learned.

It appears that due to the nascence of the topic of EIPM-related knowledge production and translation, there is not much evidence on transferring tacit knowledge and converting it to explicit knowledge in the country. Therefore, interventions for increasing the knowledge and skills of researchers and allowing them to strengthen EIPM have received increasing attention in recent years.

\section{Conclusions}

Incompatibility of health policy decisions with scientific evidence highlights the importance of creating a common language between policymakers and researchers. Developing scientific and practical interventions, educating health researchers on knowledge translation, and using mechanisms and networks for effective interaction can be constructive in this reagrd.

\section{Abbreviations}

EIPM: Evidence-based policy making

\section{Declarations}

Ethical approvals and consent to prticipate: This study was approved by the ethics committee of Tabriz University of Medcical sciences. Before starting the interview, informed consent were filled by the 
participants. We insured participants that they can exit from the study whenever they prefer.

Consentfor publication: Not applicable

Competing interests: Authors declared no conflict of interests

Availability of data and material: The datasets used and/or analysed during the current study are available from the corresponding author on reasonable request.

Funding: No funding is received.

Authors' contributions: All authors had contributions to conception and design of the study, authors LD and HM had contributions to acquisition of data, authors LD and HM and RM had contributions to analysis and interpretation of data, and all authors had contributions to drafting of manuscript and author RM revised the manuscript critically.

Acknowledgements: We are very grateful to all participants for giving their time and their useful explanations respectively.

\section{References}

1. Dunn WN. Public policy analysis: Routledge; 2015.

2. Howlett M. Policy analytical capacity and evidence-based policy-making: Lessons from Canada. Canadian Public Administration. 2009;52(2):153-75.

3. Buse K, Mays N, Walt G. Making health policy: McGraw-Hill Education (UK); 2012.

4. Rycroft-Malone J, Seers K, Titchen A, Harvey G, Kitson A, McCormack B. What counts as evidence in evidence-based practice? Journal of advanced nursing. 2004;47(1):81-90.

5. Champagne F, Lemieux-Charles L. Using knowledge and evidence in health care: multidisciplinary perspectives: University of Toronto Press; 2004.

6. Hawkes S, Aulakh BK, Jadeja N, Jimenez M, Buse K, Anwar I, et al. Strengthening capacity to apply health research evidence in policy making: Experience from four countries. Health Policy and Planning. 2016;31(2):161-70.

7. Ranganathan S, Bali Swain R. Sustainable development and global emission targets: A dynamical systems approach to aid evidence-based policy making. Sustainable Development. 2018.

8. Bosch-Capblanch X, Lavis JN, Lewin S, Atun R, Røttingen J-A, Dröschel D, et al. Guidance for evidence-informed policies about health systems: rationale for and challenges of guidance development. PLoS medicine. 2012;9(3).

9. Tudisca V, Valente A, Castellani T, Stahl T, Sandu P, Dulf D, et al. Development of measurable indicators to enhance public health evidence-informed policy-making. Health research policy and systems. 2018;16(1):47. 
10. Dakhesh S, Ostovar A, Hamidi A. From Transfer of Research Question to Promoting the Use of Evidence in the Process of Knowledge Translation: Self-Assessment of Researchers in Bushehr University of Medical Sciences. ISMJ. 2018;21(2):134-46.

11. Uneke CJ, Ezeoha A, Ndukwe C, Oyibo P, Onwe F, Bhupinder A. Enhancing policy makers' capacity for evidence-informed policy making through mentorship: A reflection on the Nigeria experience. Evidence and Policy. 2014;10(1):137-59.

12. Uneke CJ, Sombie I, Keita N, Lokossou V, Johnson E, Ongolo-Zogo P. An assessment of policymakers' engagement initiatives to promote evidence informed health policy making in Nigeria. The Pan African medical journal. 2017;27:57.

13. Mabuza LH, Govender I, Ogunbanjo GA, Mash B. African Primary Care Research: Qualitative data analysis and writing results. African journal of primary health care \& family medicine. 2014;6(1):1-5.

14. Adam T, Moat KA, Ghaffar A, Lavis JN. Towards a better understanding of the nomenclature used in information-packaging efforts to support evidence-informed policymaking in low- and middle-income countries. Implementation science : IS. 2014;9:67.

15. Andermann A, Pang T, Newton JN, Davis A, Panisset U. Evidence for Health I: Producing evidence for improving health and reducing inequities. Health research policy and systems. 2016;14:18.

16. Snilstveit B, Vojtkova M, Bhavsar A, Stevenson J, Gaarder M. Evidence \& Gap Maps: A tool for promoting evidence informed policy and strategic research agendas. Journal of clinical epidemiology. 2016;79:120-9.

17. Uneke CJ, Aulakh BK, Ezeoha AE, Ndukwe CD, Onwe F. Bridging the divide between research and policy in Nigeria: the role of a health policy advisory committee. Journal of public health policy. 2012;33(4):423-9.

18. Uneke CJ, Ezeoha AE, Uro-Chukwu HC, Ezeonu CT, Igboji J. Promoting researchers and policy-makers collaboration in evidence-informed policy-making in Nigeria: Outcome of a two-way secondment model between university and health ministry. International Journal of Health Policy and Management. 2018;7(6):522-31.

19. Brennan SE, McKenzie JE, Turner T, Redman S, Makkar S, Williamson A, et al. Development and validation of SEER (Seeking, Engaging with and Evaluating Research): a measure of policymakers' capacity to engage with and use research. Health research policy and systems. 2017;15(1):1.

20. Langlois EV, Becerril Montekio V, Young T, Song K, Alcalde-Rabanal J, Tran N. Enhancing evidence informed policymaking in complex health systems: lessons from multi-site collaborative approaches. Health research policy and systems. 2016;14:20.

21. El-Jardali F, Lavis J, Moat K, Pantoja T, Ataya N. Capturing lessons learned from evidence-to-policy initiatives through structured reflection. Health research policy and systems. 2014;12:2.

22. Cairney P, Oliver K. Evidence-based policymaking is not like evidence-based medicine, so how far should you go to bridge the divide between evidence and policy? Health research policy and systems. 2017;15(1):35. 
23. Mijumbi RM, Oxman AD, Panisset U, Sewankambo NK. Feasibility of a rapid response mechanism to meet policymakers' urgent needs for research evidence about health systems in a low income country: a case study. Implementation science : IS. 2014;9:114.

24. Juzwishin DW. Evidence informed decision-making in healthcare: the case for health technology assessment. World hospitals and health services : the official journal of the International Hospital Federation. 2010;46(1):10-2.

25. Uzochukwu B, Onwujekwe O, Mbachu C, Okwuosa C, Etiaba E, Nystrom ME, et al. The challenge of bridging the gap between researchers and policy makers: experiences of a Health Policy Research Group in engaging policy makers to support evidence informed policy making in Nigeria. Globalization and health. 2016;12(1):67.

26. Ouimet M, Lavis JN, Leon G, Ellen ME, Bedard PO, Grimshaw JM, et al. A cross-sectional survey of supports for evidence-informed decision-making in healthcare organisations: a research protocol. Implementation science : IS. 2014;9:146.

27. Makkar SR, Williamson A, Turner T, Redman S, Louviere J. Using conjoint analysis to develop a system of scoring policymakers' use of research in policy and program development. Health research policy and systems. 2015;13:35.

28. Field P, Gauld R, Lawrence M. Enhancing evidence use in public health nutrition policymaking: theoretical insights from a New Zealand case study. Health research policy and systems. 2016;14(1):84.

29. Majdzadeh R, Sadighi J, Nejat S, Mahani AS, Gholami J. Knowledge translation for research utilization: design of a knowledge translation model at Tehran University of Medical Sciences. Journal of Continuing Education in the Health Professions. 2008;28(4):270-7.

30. Kawabuchi K. Evidence-based policy making for sustainable healthcare in Japan: 2025 and beyond. Japan-hospitals : the journal of the Japan Hospital Association. 2013(32):29-37.

31. Lavis JN, Panisset U. EVIPNet Africa's first series of policy briefs to support evidence-informed policymaking. International Journal of Technology Assessment in Health Care. 2010;26(2):229-32.

32. Lavis JN, Wilson MG, Grimshaw JM, Haynes RB, Hanna S, Raina P, et al. Effects of an evidence service on health-system policy makers' use of research evidence: a protocol for a randomised controlled trial. Implementation science : IS. 2011;6:51.

33. Perrier L, Mrklas K, Lavis JN, Straus SE. Interventions encouraging the use of systematic reviews by health policymakers and managers: a systematic review. Implementation Science. 2011;6(1):43.

34. Caiaffa WT, Friche AA, Dias MA, Meireles AL, Ignacio CF, Prasad A, et al. Developing a conceptual framework of urban health observatories toward integrating research and evidence into urban policy for health and health equity. Journal of urban health : bulletin of the New York Academy of Medicine. 2014;91(1):1-16.

35. Best A, Terpstra JL, Moor G, Riley B, Norman CD, Glasgow RE. Building knowledge integration systems for evidence-informed decisions. Journal of health organization and management. 2009;23(6):627-41. 
36. Tonmukayakul U, Velasco RP, Tantivess S, Teerawattananon Y. Lessons drawn from research utilization in the maternal iodine supplementation policy development in Thailand. BMC public health. 2012;12:391.

\section{Tables}

\begin{tabular}{|l|c|c|c|c|c|}
\hline \multicolumn{5}{|c|}{ Table 1- Characteristics of interviewees } \\
& \multirow{2}{*}{ Organization } & Number of & \multicolumn{2}{|c|}{ Sex } & \multicolumn{2}{c|}{ Academic Discipline } \\
\cline { 3 - 6 } & participants & Male & Female & $\begin{array}{c}\text { Health } \\
\text { policy }\end{array}$ & $\begin{array}{c}\text { Other } \\
\text { disciplines }\end{array}$ \\
\hline Parliament Health Research Center & 2 & 0 & 2 & 1 & 1 \\
\hline $\begin{array}{l}\text { National Health policy Research } \\
\text { Institue }\end{array}$ & 2 & 1 & 1 & 0 & 2 \\
\hline Applied Health Research Center & & & & & 2 \\
\hline Tabriz University of Medical Sciences & 3 & 1 & 3 & 2 & 2 \\
\hline $\begin{array}{l}\text { Health Research and knowledge } \\
\text { Translation Institue }\end{array}$ & 3 & 0 & 3 & 1 & 2 \\
\hline Tehran University of Medical Sciences & 4 & 2 & 2 & 2 & 2 \\
\hline \multicolumn{1}{|c|}{ Total } & $\mathbf{1 8}$ & $\mathbf{5}$ & $\mathbf{1 3}$ & $\mathbf{9}$ & $\mathbf{9}$ \\
\hline
\end{tabular}

\section{Supplementary Files}

This is a list of supplementary files associated with this preprint. Click to download.

- AppendixTopicguide.docx 